\title{
The activity of the glyoxylate cycle in peroxisomes of Candida albicans depends on a functional $\beta$-oxidation pathway: evidence for reduced metabolite transport across the peroxisomal membrane
}

\section{Correspondence \\ Ben Distel \\ b.distel@amc.uva.nl}

Received 6 May 2008

Revised 25 June 2008

Accepted 25 June 2008

\author{
Katarzyna Piekarska, ${ }^{1} \dagger$ Guy Hardy, ${ }^{1}$ Els Mol, ${ }^{1}$ Janny van den Burg, ${ }^{1}$ \\ Karin Strijbis, ${ }^{1}$ Carlo van Roermund, ${ }^{2}$ Marlene van den Berg ${ }^{1}$ \\ and Ben Distel ${ }^{1}$
}

\author{
${ }^{1}$ Department of Medical Biochemistry, Academic Medical Center, Meibergdreef 15, 1105 AZ \\ Amsterdam, The Netherlands \\ ${ }^{2}$ Department of Genetic Metabolic Diseases, Academic Medical Center, Meibergdreef 15, 1105 AZ \\ Amsterdam, The Netherlands
}

\begin{abstract}
The glyoxylate cycle, a metabolic pathway required for generating $\mathrm{C}_{4}$ units from $\mathrm{C}_{2}$ compounds, is an important factor in virulence, in both animal and plant pathogens. Here, we report the localization of the key enzymes of this cycle, isocitrate lyase (Icl1; EC 4.1.3.1) and malate synthase (Mls1; EC 2.3.3.9), in the human fungal pathogen Candida albicans.

Immunocytochemistry in combination with subcellular fractionation showed that both Icl1 and Mls1 are localized to peroxisomes, independent of the carbon source used. Although lcl1 and Mls1 lack a consensus type I peroxisomal targeting signal (PTS1), their import into peroxisomes was dependent on the PTS1 receptor Pex5p, suggesting the presence of non-canonical targeting signals in both proteins. Peroxisomal compartmentalization of the glyoxylate cycle is not essential for proper functioning of this metabolic pathway because a pex $5 \Delta / \Delta$ strain, in which Icl 1 and Mls1 were localized to the cytosol, grew equally as well as the wild-type strain on acetate and ethanol. Previously, we reported that a fox $2 \Delta / \Delta$ strain that is completely deficient in fatty acid $\beta$ oxidation, but has no peroxisomal protein import defect, displayed strongly reduced growth on non-fermentable carbon sources such as acetate and ethanol. Here, we show that growth of the fo $2 \Delta / \Delta$ strain on these carbon compounds can be restored when Icl1 and Mls 1 are relocated to the cytosol by deleting the PEX5 gene. We hypothesize that the fox $2 \Delta / \Delta$ strain is disturbed in the transport of glyoxylate cycle products and/or acetyl-CoA across the peroxisomal membrane and discuss the possible relationship between such a transport defect and the presence of giant peroxisomes in the fox $2 \Delta / \Delta$ mutant.
\end{abstract}

\section{INTRODUCTION}

The glyoxylate cycle, present in bacteria, yeasts and plants, allows utilization of non-fermentable carbon sources such as acetate, ethanol and fatty acids by converting the produced acetyl-CoA into $\mathrm{C}_{4}$ compounds that can be used for the biosynthesis of macromolecules (Kornberg \& Krebs, 1957). This function has been confirmed through the analysis of bacterial and fungal mutants lacking either isocitrate lyase (Icl1; EC 4.1.3.1) or malate synthase (Mls1;

†Present address: University of Manchester, The Michael Smith Building A1030, Oxford Road, Manchester M13 9PT, UK.

Abbreviations: Icl1, isocitrate lyase; Mls1, malate synthase; PEX, peroxisome biogenesis gene/protein; PTS1, peroxisomal targeting signal 1 ; TCA, tricarboxylic acid.
EC 2.3.3.9), the key enzymes of the glyoxylate cycle. Loss of Icl1 or Mls1 results in the inability of these mutants to grow on acetate, ethanol or fatty acids (Hartig et al., 1992; Lorenz \& Fink, 2001; McKinney et al., 2000; Munoz-Elias \& McKinney, 2005; Pellicer et al., 1999). There is a renewed interest in the glyoxylate cycle that is based on recent observations suggesting a key role for this metabolic pathway in survival of bacterial and fungal pathogens within macrophages, phagocytic cells of the innate immune system that form the first line of defence against microbial infections. Whole-genome DNA microarrays have shown an upregulation of glyoxylate cycle genes and concomitant induction of genes associated with gluconeogenesis when Candida albicans, a human fungal pathogen, is internalized by macrophages (Lorenz et al., 2004). Deletion of the ICL1 
gene resulted in a mutant $C$. albicans strain that showed reduced virulence in a mouse model, providing strong support for the requirement of the glyoxylate cycle for pathogenesis of this fungus (Lorenz \& Fink, 2001). Similarly, the persistence of Mycobacterium tuberculosis in macrophages is dependent on a functional glyoxylate cycle (McKinney et al., 2000; Munoz-Elias \& McKinney, 2005). For both $C$. albicans and $M$. tuberculosis it has been suggested that the organism relies heavily on lipid catabolism for survival within the human host (Boshoff \& Barry, 2005; Lorenz \& Fink, 2002). However, we have recently shown that fatty acid metabolism is not essential for virulence of $C$. albicans, indicating that in vivo the acetyl-CoA that feeds the glyoxylate cycle may be derived from other, simple, carbon sources (Piekarska et al., 2006). In support of this, Ramírez \& Lorenz (2007) recently reported that the ability to utilize different non-fermentable carbon sources contributes to the virulence of $C$. albicans. Since the metabolism of these carbon compounds requires a functional glyoxylate cycle and this metabolic pathway is absent from mammals, Icl1 and Mls1 are potential targets for the development of drugs to combat bacterial and fungal infections.

The glyoxylate cycle consists of five enzymic activities, two of which are unique to the cycle, namely Icll and Mls1, while the other three activities, citrate synthase (EC 2.3.3.1), aconitase (EC 4.2.1.3) and malate dehydrogenase (EC 1.1.1.37), are shared with the tricarboxylic acid (TCA) cycle and are often carried out by isoenzymes. In the $C$. albicans genome, single genes exist for Icl1 (orf19.6844), Mls1 (orf19.4833) and citrate synthase (orf19.4393), whereas there are three encoding malate dehydrogenase (orf19.7481, orf19.4602 and orf19.5223) and two for aconitase (orf19.6385 and orf19.6632). Studies in fungi have shown that the key enzymes of the glyoxylate cycle, Icl1 and Mls1, are often compartmentalized in peroxisomes, the other enzymic steps being extra-peroxisomal (either cytosolic or mitochondrial) (Hikida et al., 1991; Maeting et al., 1999; Tanaka \& Ueda, 1993; Titorenko et al., 1998; Valenciano et al., 1996). Saccharomyces cerevisiae seems to be an exception to this rule: Icll is a cytosolic enzyme (McCammon et al., 1990) and Mls1 is localized either to the peroxisome or to the cytosol depending on the growth conditions (Kunze et al., 2002). These data in conjunction with the observation that $S$. cerevisiae pex mutants lacking functional peroxisomes can grow on ethanol and acetate as sole carbon source imply that the glyoxylate cycle can function in the cytosol, at least in $S$. cerevisiae.

The import of proteins into peroxisomes is mediated by two cycling receptors: Pex5p and Pex7p (reviewed by Purdue \& Lazarow, 2001). In the cytosol, Pex5p binds to proteins carrying a type I peroxisomal targeting signal (PTS1), which is a carboxyl-terminal tripeptide with the consensus sequence S/A/C-K/R/H-L/M (Gould et al., 1989; Swinkels et al., 1992). However, depending on the species and protein under study the carboxyl-terminal tripeptide may deviate from the consensus, and residues just upstream of it also can contribute to Pex5p binding and peroxisomal targeting (Lametschwandtner et al., 1998; Purdue \& Lazarow, 1996). Proteins delivered to the peroxisome via the Pex7p receptor possess a PTS2, a bipartite amino acid motif with the consensus sequence $\mathrm{R} /$ K-L/V/I-x-1-H/Q-L/A (Gietl et al., 1994; Glover et al., 1994b) present in the amino terminus of these proteins. A number of proteins can be imported into peroxisomes independent of a recognizable PTS1 or PTS2 (Elgersma et al., 1995; Klein et al., 2002; Ozimek et al., 2006; Small et al., 1988). Subsequent studies have shown that, although the targeting signal is as yet not characterized, Pex $5 \mathrm{p}$ mediates the peroxisomal sorting of these proteins (Elgersma et al., 1995; Klein et al., 2002; Ozimek et al., 2006). Finally, some proteins can reach the organelle by association with another subunit or protein that possesses a functional targeting signal, a process referred to as 'piggy backing' (Glover et al., 1994a; McNew \& Goodman, 1994; Yang et al., 2001). The PTS1 and PTS2 pathways converge at the peroxisomal membrane, where the cargo-loaded receptors dock onto a complex consisting of Pex13p and Pex14p (and Pex17p in S. cerevisiae). Subsequently, the cargo is released and translocated across the peroxisomal membrane, after which the receptors recycle back to the cytosol for a new round of import (Purdue \& Lazarow, 2001). Although the early steps in peroxisomal protein import are rather well defined, very little is known about the events following docking.

Here we have studied the localization of the two key enzymes of the glyoxylate cycle, Icll and Mls1, in the human fungal pathogen $C$. albicans and show that both enzymes are localized to peroxisomes in a Pex5pdependent way. We also provide evidence that the glyoxylate cycle no longer functions in giant peroxisomes of the fatty acid $\beta$-oxidation mutant fox $2 \Delta / \Delta$. The activity of the glyoxylate cycle in the fox $2 \Delta / \Delta$ mutant is restored when Icl1 and Mls1 are relocated to the cytosol through deletion of the PEX5 gene in this strain. Our data show that the glyoxylate cycle can function in the cytosol also in $C$. albicans and suggest that the giant peroxisomes of the fox $2 \Delta / \Delta$ strain are impaired in metabolite transport across the membrane. Possible mechanisms that may explain the reduced peroxisomal metabolite transport are discussed.

\section{METHODS}

Strains, media and culture conditions. $C$. albicans and $S$. cerevisiae strains used in this study are listed in Table 1. C. albicans deletion strains are derivatives of BWP17 (Wilson et al., 1999). Gene deletions in S. cerevisiae were constructed in BJ1991 (Jones, 1977). The solid minimal medium used for selection and growth of both $C$. albicans and $S$. cerevisiae transformants contained $0.67 \%(\mathrm{w} / \mathrm{v})$ yeast nitrogen base (YNB) w/o amino acids (Difco), $2 \%(\mathrm{w} / \mathrm{v})$ glucose, $2 \%(\mathrm{w} / \mathrm{v})$ agar, amino acids $\left(20-30 \mu \mathrm{g} \mathrm{ml}^{-1}\right)$ and either $80 \mu \mathrm{g}$ uridine $\mathrm{ml}^{-1}(C$. albicans) or $20 \mu \mathrm{g}$ uracil $\mathrm{ml}^{-1}$ (S. cerevisiae) as needed. For transformations using the dominant selection marker SAT1, a $24 \mathrm{~h}$ incubation under non-selective conditions was applied prior to 
Table 1. Yeast strains used in this study

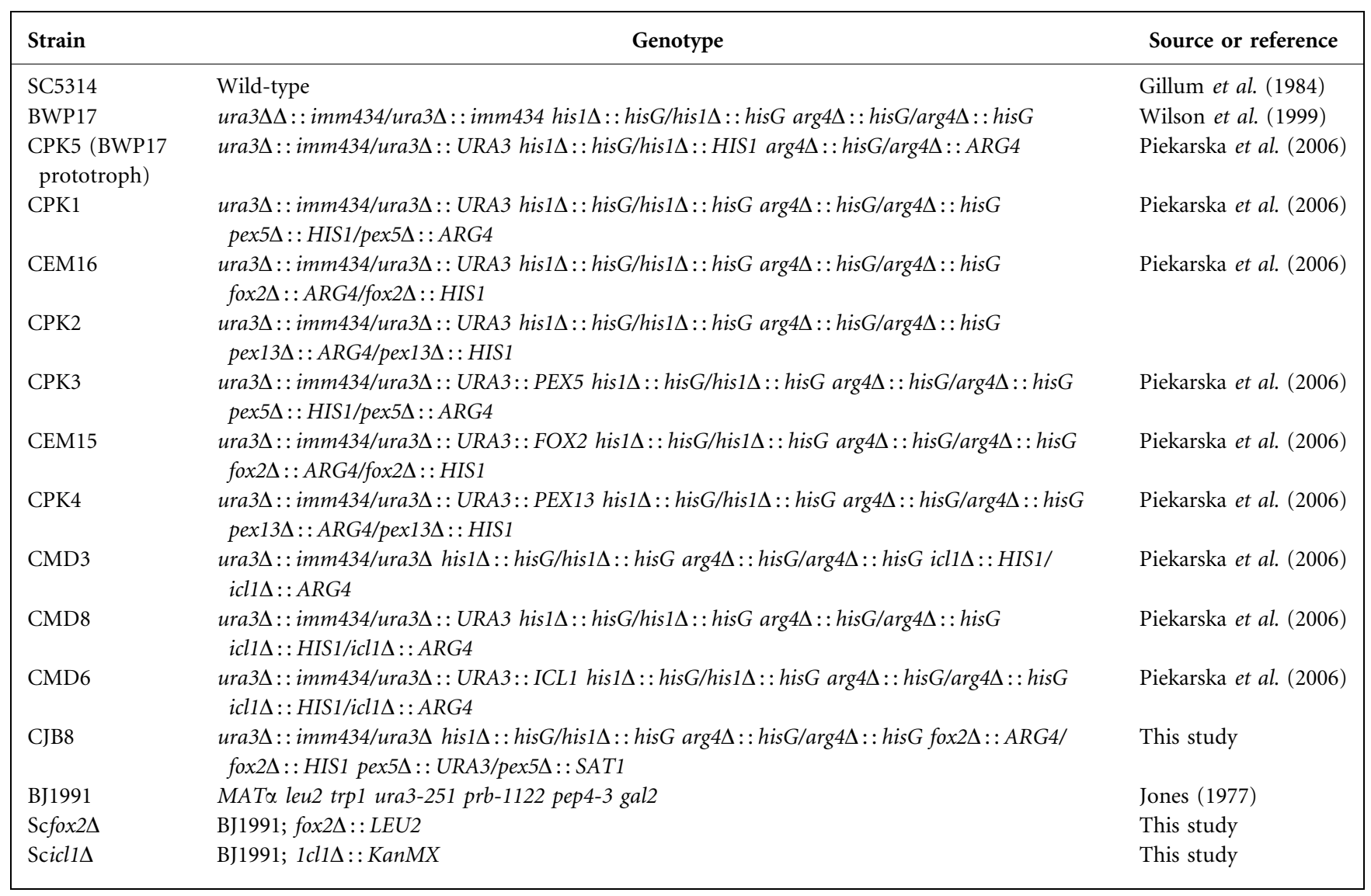

replica plating on YPD + Uri $[2 \%(\mathrm{w} / \mathrm{v})$ bactopeptone, $1 \%(\mathrm{w} / \mathrm{v})$ yeast extract, $2 \%(\mathrm{w} / \mathrm{v})$ glucose and $80 \mu \mathrm{g}$ uridine $\mathrm{ml}^{-1}$ ] with $200 \mu \mathrm{g}$ nourseothricin $\mathrm{ml}^{-1}$ (clonNAT, Werner Bioagents). Plates used for spot assays had the same composition and contained $2 \%(\mathrm{w} / \mathrm{v})$ glucose, $2 \%(\mathrm{v} / \mathrm{v})$ ethanol, $2 \%(\mathrm{v} / \mathrm{v})$ glycerol, $2 \%(\mathrm{w} / \mathrm{v})$ sodium citrate or $2 \%(\mathrm{w} / \mathrm{v})$ sodium acetate $(\mathrm{pH} 5.0)$ as a carbon source. The liquid medium used for culturing of the cells for total protein isolation, subcellular fractionation and immunoelectron microscopy contained $0.5 \%(\mathrm{w} / \mathrm{v})$ potassium phosphate buffer, $\mathrm{pH} 6.0,0.3 \%(\mathrm{w} / \mathrm{v})$ yeast extract, $0.5 \%(\mathrm{w} / \mathrm{v})$ peptone and, as a carbon source, either $0.1 \%$ $(\mathrm{v} / \mathrm{v})$ oleate and $0.2 \%(\mathrm{v} / \mathrm{v})$ Tween 40 , or $2 \%(\mathrm{v} / \mathrm{v})$ ethanol. All yeast strains were grown at $28{ }^{\circ} \mathrm{C}$ unless otherwise stated.

Table 2. Primers used in this study

\begin{tabular}{|c|c|c|}
\hline Primer & Sequence $\left(5^{\prime}-3^{\prime}\right)$ & Description \\
\hline PEX5-F extension & GATTGGTCTGGACTATAATTTTGGATTTTCGAAAA & Extension primer for disruption \\
\hline PEX5-R extension & AGTCATTTTCTCATTACAGCTAGAAAAATAATAAT & Extension primer for disruption \\
\hline CaPex5R & GTTGGTGGTAGGAAGCGTTG & Diagnostic primer \\
\hline Verif-Ca-U4 & ACGAATCAATGGCACTACAGC & Diagnostic primer \\
\hline Verif-Ca-U5 & GATTAGATGATAAAGGTGATGG & Diagnostic primer \\
\hline JB12-SAT1-inR & TTCGTTGGCAATAAATCTTGG & Diagnostic primer SAT internal \\
\hline JB13-SAT1-inF & AGCACAGGATGACGCCTAAC & Diagnostic primer SAT internal \\
\hline A5 & TTTAATGTGCGATGGGTTCA & Diagnostic primer ARG internal \\
\hline
\end{tabular}


Gene disruptions and plasmid constructions. For gene deletions in C. albicans, a PCR-based procedure with primers carrying 60 $70 \mathrm{bp}$ regions of homology to the $5^{\prime}$ and $3^{\prime}$ flanking sequences of the ORF was used (Wilson et al., 1999). Primers are listed in Table 2. The construction of the pex $5 \Delta / \Delta$ (CPK1), fox $2 \Delta / \Delta$ (CEM16), pex $13 \Delta / \Delta$ (CPK2) and icl1 $\Delta / \Delta$ (CDM8) strains and their complemented derivatives (CPK3, CEM15, CPK4 and CDM6, respectively) has been described before (Piekarska et al., 2006).To delete the PEX5 gene in the fox $2 \Delta / \Delta$ strain CPK12, two disruption cassettes were made by PCR with primer pair CaPex $5 \Delta$-F-FA and CaPex $5 \Delta$-R-FA in combination with extension primers (PEX5-F extension and PEX5$\mathrm{R}$ extension) on plasmids pFA-URA and pFA-SAT1, respectively (Gola et al., 2003). The latter plasmid contains the dominant marker $S A T 1$ that confers resistance to nourseothricin. Sequential transformation of these cassettes into CPK12 resulted in strain CJB8 $($ fox $2 \Delta / \Delta$ pex $5 \Delta / \Delta)$. All $C$. albicans disruption strains were made prototrophic by transformation of a linearized pLUBP vector, which contains the complete URA3 gene and the flanking IRO1 gene. The $S$. cerevisiae icl1 $1 \Delta$ and fox $2 \Delta$ strains were generated by one-step PCRmediated gene disruption using $\operatorname{KanMX}$ and LEU2, respectively (Gueldener et al., 2002). All constructed strains were verified by diagnostic PCR and Southern blotting.

Spot assay. Cells were pre-grown in minimal liquid medium containing $0.3 \%$ glucose for at least $24 \mathrm{~h}$, washed with water and resuspended at a concentration of $\sim 2.7 \times 10^{7}$ cells $\mathrm{ml}^{-1}\left(\mathrm{OD}_{600} 1\right)$. Cells were serially diluted ( $1: 10$ dilutions) in water and $5 \mu$ l aliquots of each dilution were applied to agar plates. Plates were incubated at $28{ }^{\circ} \mathrm{C}$ for 3 days (glucose) or 5 days (acetate, ethanol, citrate and glycerol).

Subcellular fractionation of C. albicans. For subcellular fractionation, C. albicans cells were pre-grown in minimal $0.3 \%$ glucose medium for at least $24 \mathrm{~h}$, transferred to $200 \mathrm{ml}$ rich oleic acid or ethanol medium and grown to the late exponential phase. Subcellular fractionation was performed essentially as previously described (Aitchison \& Rachubinski, 1990; Kamiryo et al., 1982). Briefly, cells were collected by centrifugation, washed three times with water and converted to spheroplasts with Zymolyase $100 \mathrm{~T}$ ( $0.25 \mathrm{mg}$ per g cells) in buffer $\mathrm{Z}$ ( $5 \mathrm{mM}$ MOPS pH 7.2, $0.5 \mathrm{M} \mathrm{KCl}$ and $10 \mathrm{mM} \mathrm{Na}_{2} \mathrm{SO}_{3}$ ). Spheroplasts were collected by centrifugation, resuspended in buffer $\mathrm{F}$ [5.5 mM MOPS pH 7.2, $5 \%$ (w/v) Ficoll 400, 0.6 M sorbitol, $0.5 \mathrm{mM}$ EDTA, $0.1 \%(\mathrm{v} / \mathrm{v})$ ethanol] and homogenized in a grinding vessel (Potter-Elvejhem) by 20 down-and-up strokes with a tight-fitting pestle. The homogenate was centrifuged for $10 \mathrm{~min}$ at $1000 \mathrm{~g}$ and the resulting post-nuclear supernatant $(\mathrm{H})$ was fractionated into an organellar pellet (P) and cytosolic supernatant (S) fraction by centrifugation for $20 \mathrm{~min}$ at $20000 \mathrm{~g}$.

Antibodies and immunoblotting. Antibodies against S. cerevisiae thiolase and catalase and their cross-reactivity with the corresponding peroxisomal proteins in $C$. albicans have been described before (Piekarska et al., 2006). Polyclonal rabbit antibodies against $S$. cerevisiae Mls1 (Kunze et al., 2002), S. cerevisiae Zwf1 (glucose-6phosphate dehydrogenase) (Sigma Aldrich) and Ashbya gossypii Icl1 (Schmidt et al., 1996) were used at dilutions of $1: 1000,1: 500$ and $1: 10000$, respectively. Immunoreactive complexes were visualized with horseradish peroxidase-coupled goat-anti-rabbit IgG and the ECL system of Amersham Biosciences.

Enzyme assays. Preparation of cell-free extracts and enzyme assays were performed essentially as described by de Jong-Gubbels et al. (1995) with the following modifications. Extracts were freshly prepared and the assays were carried out in a UVIKON 820 double-beam spectrophotometer (Kontron) at room temperature. The malate synthase assay was started with acetyl-CoA instead of glyoxylate.
Morphometric analysis of peroxisomes. Images were acquired with an SIS MegaviewII camera of randomly selected cells at a magnification of $\times 5500(100$ pixels $=0.44 \mu \mathrm{m})$. Using QWin (Leica) in an interactive mode, all peroxisomal structures in a cell as well as the whole cell were traced to determine their cross-sectional areas. The mean peroxisome area was calculated by dividing the total peroxisome area by the total number of peroxisomes counted.

Miscellaneous. The following procedures were performed according to published methods: nucleic acid manipulations (Sambrook et al., 1989), C. albicans transformation (Walther \& Wendland, 2003), preparation of whole-cell protein extracts (Elgersma et al., 1996), SDS-PAGE and immunoblotting (Bottger et al., 2000), and immunoelectron miscroscopy (Gould et al., 1990).

\section{RESULTS}

\section{Icl1 and MIs1 are localized to peroxisomes in a Pex5p-dependent manner}

Both CaIcl1 and CaMls1 lack a typical PTS1 or PTS2 motif in their primary sequence. To determine their subcellular distribution, we performed biochemical fractionation and immunoelectron miscroscopy experiments with $C$. albicans cells grown on two different non-fermentable-carbon sources: ethanol and oleic acid. The choice of the two media was based on a previous study in S. cerevisiae in which it was shown that the compartmentalization of Mls1 may vary with the carbon source used (Kunze et al., 2002). First, we assessed the specificity and cross-reactivity of the antibodies used in this study by immunoblotting of total protein extracts (Fig. 1a). The antibody raised against Ashbya gossypii Icll reacted with a single protein band with an apparent molecular mass of $62 \mathrm{kDa}$ in wild-type C. albicans and S. cerevisiae cells, while this band was absent in the Caicl1 deletion strain. Similarly, the $S$. cerevisiae Mls1 antibody recognized a single protein band in both $S$. cerevisiae and C. albicans lysates with a molecular mass of about $61 \mathrm{kDa}$. No band was present in the extracts of $S$. cerevisiae $m l s 1 \Delta$ cells, confirming the specificity of the antibody. Next, we carried out subcellular fractionation experiments to determine the distribution of Mls1 and Icl1 in C. albicans cells grown in ethanol- or oleic acid-containing media (Fig. $1 \mathrm{~b}$ and c). In addition to wild-type cells we used pex5 $5 / \Delta$ and pex $13 \Delta / \Delta$ cells as controls. The pex $5 \Delta / \Delta$ mutant lacking Pex5p is specifically disturbed in the peroxisomal import of PTS1 proteins whereas in the pex13 $\Delta / \Delta$ strain both PTS1 and PTS2 import pathways are blocked. Differential centrifugation of a homogenate $(\mathrm{H})$, obtained by osmotic lysis of spheroplasts, resulted in an organellar pellet fraction (P) containing mitochondria and peroxisomes, and a cytosolic supernatant fraction (S). Equal portions of each fraction were analysed by immunoblotting with the Mls1 and Icl1 antibodies. As a control, antibodies against thiolase (a PTS2 protein) and catalase (a PTS1 protein) were used, both of which are proven peroxisomal proteins in C. albicans (Piekarska et al., 2006). In both oleic acid- and ethanol-grown wild-type cells Mls1 and Icl1 were predominantly present in the pellet fraction. In the pex $5 \Delta / \Delta$ mutant both proteins completely mislocalized to the supernatant fraction, independently of the carbon source used. 
(a)
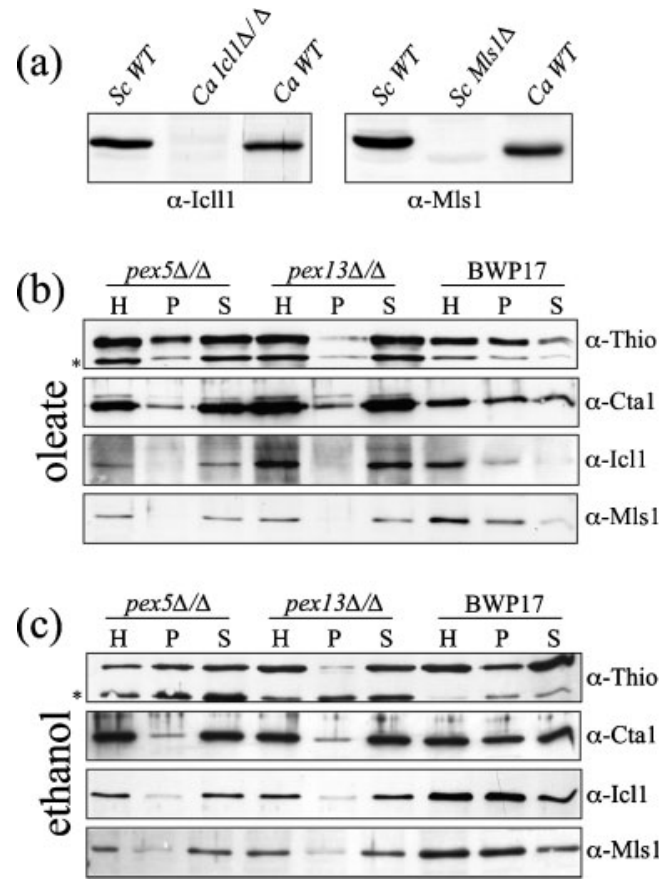

Fig. 1. Subcellular distribution of Icl1 and Mls1 in oleic acid- and ethanol-grown $C$. albicans strains. (a) The specificity of the antibodies to A. gossypii Icl1 (left panel) and S. cerevisiae Mls1 (right panel) was determined by immunoblotting using total protein extracts of the indicated $C$. albicans and $S$. cerevisiae strains. Equal amounts of total protein were loaded in each lane. (b, c) Oleic acid-grown (b) or ethanol-grown (c) wild-type (BWP17), pex $5 \Delta / \Delta$ and pex $13 \Delta / \Delta$ strains were subjected to subcellular fractionation as described in Methods. Equivalent volumes of the homogenate $(H)$, organellar pellet $(P)$ and supernatant $(S)$ fractions were electrophoresed on SDS-polyacrylamide gels, followed by transfer to nitrocellulose. The blot was probed with antibodies to proteins indicated on the right. Cta1, catalase; thio, thiolase. The asterisk indicates a cross-reactive non-specific band.

Comparable results were obtained with the pex13 $\Delta / \Delta$ strain. The relatively large amounts of the peroxisomal marker proteins thiolase and catalase in the cytosolic fraction of wild-type cells suggested that during the fractionation procedure some peroxisomes are disrupted and matrix proteins leak out, a phenomenon that is quite often seen because peroxisomes are very fragile organelles.

To firmly establish the subcellular localization of Icll and Mls1, we performed immunoelectron microscopy (Fig. 2). The Icl1 and Mls1 antibodies almost exclusively labelled peroxisomal profiles in oleic acid- and ethanol-grown wildtype cells. In pex $5 \Delta / \Delta$ cells cultured on oleic acid gold particles were only found in the cytosol with both antibodies, substantiating the cytosolic localization of Icl1 and Mls1 in this strain inferred from the subcellular fractionation experiments of Fig. 1. Anti-thiolase labelling of pex $5 \Delta / \Delta$ cells showed that the PTS2 protein thiolase is still imported in peroxisomal remnants, as can be seen by the gold particles decorating membranous structures in these cells. These data confirm the PTS1-specific import defect in this mutant strain. Similar results were obtained with the pex $5 \Delta / \Delta$ strain grown on ethanol (results not shown). Together, these data suggest that Icl1 and Mls1 are peroxisomal in oleic acid- and ethanol-grown cells and imply that Pex5p mediates their import into peroxisomes.

\section{The glyoxylate cycle can function both in the peroxisome and in the cytosol}

Next we addressed the question whether a peroxisomal localization of Icll and Mls1 is required for proper functioning of the glyoxylate cycle. To this end, the capacity of wild-type cells to grow on solid minimal ethanol- or acetate-containing media was compared to that of the pex5 $\Delta / \Delta$ and icll $\Delta / \Delta$ mutant strains (Fig. 3a). The pex $5 \Delta / \Delta$ mutant grew equally as well as the wild-type strain on acetate and ethanol, while the $i c l 1 \Delta / \Delta$ strain was unable to grow on either carbon source. Growth on glucose and glycerol (a non-fermentable $\mathrm{C}_{3}$ carbon source) was similar for all strains.

These results suggest that the glyoxylate cycle can function both in the peroxisome and in the cytosol.

\section{Growth of the fatty acid $\beta$-oxidation mutant fox $2 \Delta / \Delta$ on non-fermentable carbon sources can be restored by relocation of Icl1 and MIs1 to the cytosol}

Recently, we reported that a fox $2 \Delta / \Delta$ mutant, which lacks the peroxisomal multifunctional enzyme and is completely deficient in peroxisomal fatty acid $\beta$-oxidation but has no PTS1 or PTS2 import defect, showed a strongly reduced growth on acetate- and ethanol-containing media (Piekarska et al., 2006 and Fig. 3a). In contrast, growth of the fox $2 \Delta / \Delta$ mutant on glucose or on glycerol was comparable to that of wild-type cells (Fig. 3a). The addition of acetic acid or ethanol in the same concentrations to plates containing glucose did not affect growth of the fox $2 \Delta / \Delta$ mutant compared to glucose-only plates, suggesting that the strongly reduced growth on acetate and ethanol is due to the inability of the mutant to metabolize $\mathrm{C}_{2}$ carbon sources efficiently and is not caused by toxic effects of these compounds (results not shown). This growth phenotype of the $C$. albicans fox $2 \Delta / \Delta$ strain was rather unexpected because the $S$. cerevisiae fox $2 \Delta$ mutant is not deficient for growth on acetate or ethanol (Fig. $3 b$ and data not shown).

Since it has been shown that in S. cerevisiae Mls1 and Icl1 are both cytosolic in ethanol- and acetate-grown cells (Kunze et al., 2002) we suspected a correlation between the peroxisomal compartmentalization of these key enzymes of the glyoxylate cycle in $C$. albicans and the inability of the fox $2 \Delta / \Delta$ mutant to grow on $C_{2}$ carbon sources. To test this hypothesis we disrupted both alleles of the PEX5 gene in the fox $2 \Delta / \Delta$ strain and assessed 


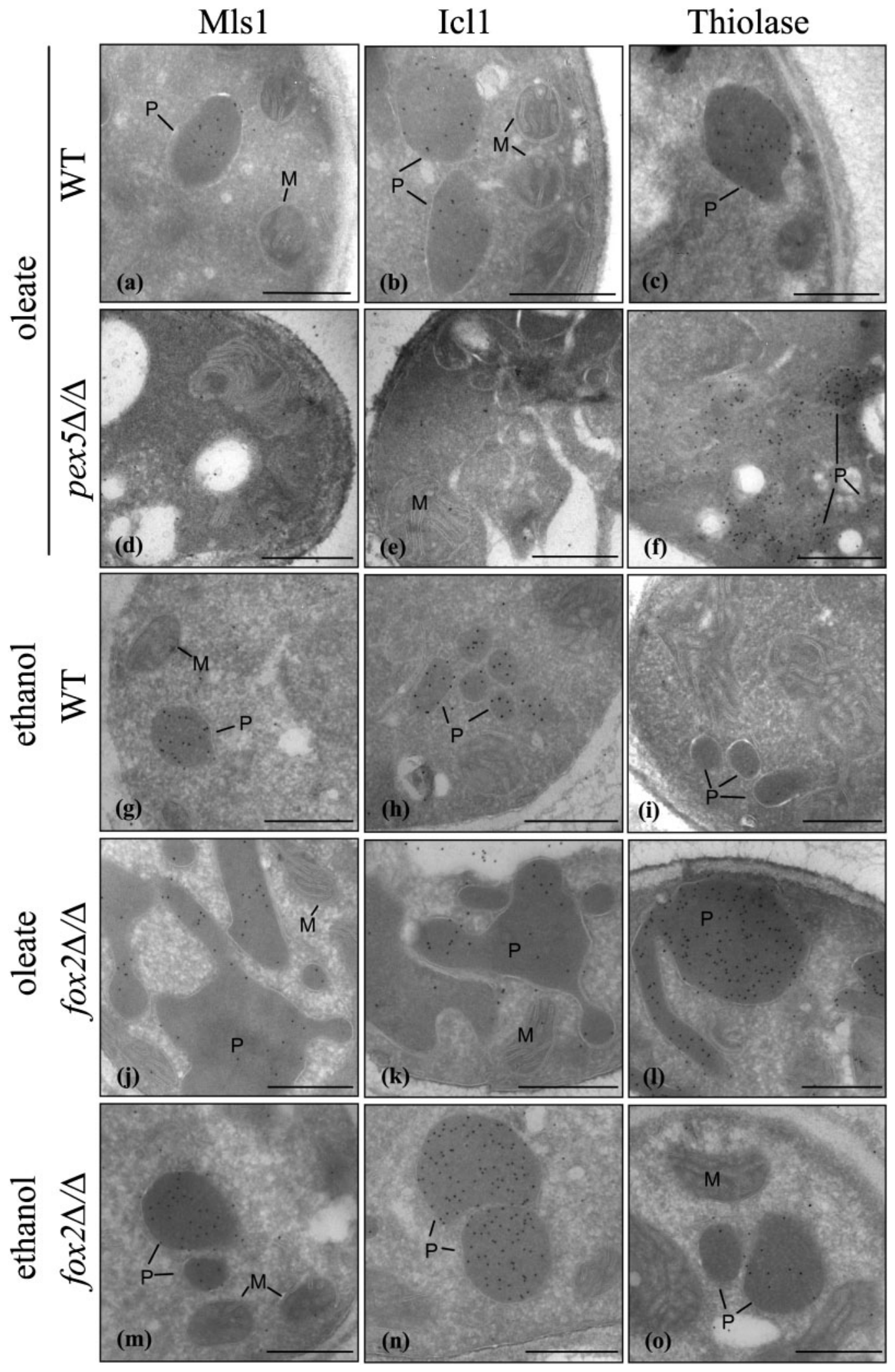

Fig. 2. Peroxisome morphology and subcellular localization of Icl1 and Mls1 in wild-type, pex $5 \Delta / \Delta$ and fox $2 \Delta / \Delta$ cells. Electron microscopy analysis was performed on wild-type cells (a-c, g-i), pex5 $\Delta / \Delta$ cells $(d-f)$ and fox $2 \Delta / \Delta$ cells $(j-0)$ grown on medium containing oleic acid $(a-f, j-l)$ or ethanol $(g-i, m-o)$. Cryosections were labelled with primary antibodies specific for Mls1 $(\mathrm{a}, \mathrm{d}, \mathrm{g}, \mathrm{j}$ and $\mathrm{m}$ ), Icl1 (b, e, h, k and $\mathrm{n}$ ) or thiolase (c, f, i, I and o) and immunogold particles coupled to protein A. P, peroxisome; $\mathrm{M}$, mitochondrion. Bars, $0.5 \mu \mathrm{m}$. 
(a)

\begin{tabular}{|c|c|c|c|c|c|}
\hline & $\frac{10 \text { - fold dilutions }}{\text { glucose }}$ & $\frac{10 \text { - fold dilutions }}{\text { acetate }}$ & $\frac{10 \text { - fold dilutions }}{\text { ethanol }}$ & $\underset{\text { citrate }}{\stackrel{10 \text { - fold dilutions }}{\longrightarrow}}$ & $\frac{10 \text { - fold dilutions }}{\text { glycerol }}$ \\
\hline $\begin{array}{r}\text { Wild-type } \\
\text { pex } 5 \Delta / \Delta \\
\text { fox } 2 \Delta / \Delta \\
/ \Delta \operatorname{pex} 5 \Delta / \Delta \\
\Delta / \Delta+F O X 2 \\
\text { icll } \Delta / \Delta\end{array}$ & 00 & 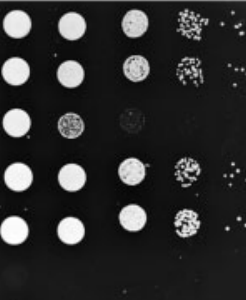 & 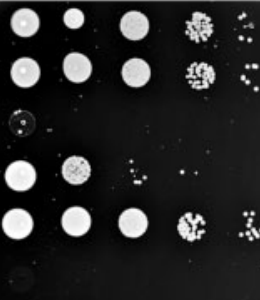 & $\begin{array}{llll}0 & 0 & 0 & 8 \\
0 & 0 & 0 & 4 \\
0 & 4 & & \\
0 & 4 & 5 & \\
0 & 0 & 0 & 0\end{array}$ & 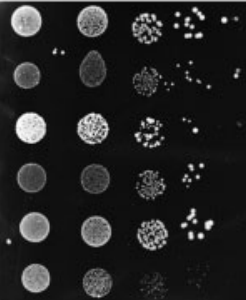 \\
\hline
\end{tabular}

(b)

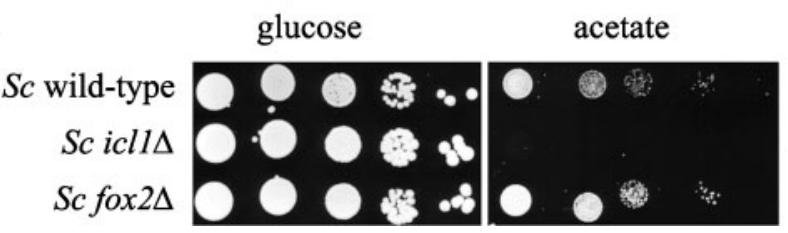

Fig. 3. Growth characteristics of wild-type and mutant strains on different carbon sources. Cells were pre-grown on $0.3 \%$ glucose-containing medium, washed, resuspended at a concentration of about $2.7 \times 10^{7} \mathrm{cells} \mathrm{ml}^{-1}$ and serially diluted (1:10 dilutions). Aliquots $(5 \mu \mathrm{l})$ of each dilution were spotted onto plates. The picture was taken after 3 days (glucose) or 5 days (acetate, ethanol, glycerol and citrate) of incubation at $28{ }^{\circ} \mathrm{C}$.

growth of the double deletion strain on glucose, ethanol and acetate. Deletion of the PEX5 gene in the fox $2 \Delta / \Delta$ strain completely restored its ability to grow on acetate, while growth on ethanol was partially restored (Fig. 3a). Ramírez \& Lorenz (2007) reported recently that the fox $2 \Delta$ / $\Delta$ mutant is not only unable to utilize acetate and ethanol $\left(\mathrm{C}_{2}\right.$ carbon sources) but also grows poorly on the $\mathrm{C}_{6}$ carbon source citric acid. A similar phenotype was observed for a strain lacking Icl1, indicating that glyoxylate cycle function is also required for the utilization of citrate. Growth assays confirmed the poor citrate utilization phenotype of the fox $2 \Delta / \Delta$ mutant, which could be partially restored by deletion of the PEX5 gene (Fig. 3a). Taken together, these results suggest that in the fox $2 \Delta / \Delta$ strain the glyoxylate cycle cannot function optimally in the peroxisomal compartment and that glyoxylate function can largely be restored by deletion of Pex $5 \mathrm{p}$ and relocation of Mls1 and Icl1 to the cytosol.

\section{Icl1 and Mls1 protein levels and activities are not reduced in the fox $2 \Delta / \Delta$ strain}

One possible explanation for the strongly reduced growth of the fox $2 \Delta / \Delta$ cells on ethanol, acetate and citrate is that the glyoxylate cycle enzymes Icl1 and Mls1 are less stable or less active in peroxisomes of the mutant strain. To test this, protein levels and activities of Icll and Mls1 were determined in ethanol- and acetate-grown wild-type, pex $5 \Delta / \Delta$, fox $2 \Delta / \Delta$, fox $2 \Delta / \Delta$ complemented, fox $2 \Delta / \Delta$ pex $5 \Delta / \Delta$ and $i c l 1 \Delta / \Delta$ cells. Immunoblot analysis revealed that Icl1 and Mls1 were present at similar levels in wildtype, fox $2 \Delta / \Delta$, fox $2 \Delta / \Delta$ complemented and fox $2 \Delta / \Delta$ pex $5 \Delta /$
$\Delta$, independent of the carbon source used (Fig. 4). In the pex $5 \Delta / \Delta$ strain grown on ethanol Icl1 levels appeared to be reduced, a phenotype that was also observed, although to a lesser extent, in acetate-grown pex $5 \Delta / \Delta$ cells. Icll was absent in the $i c l 1 \Delta / \Delta$ strain, confirming the mutant phenotype. Quantification of Icll and Mls1 enzyme activities in protein extracts of these six strains largely confirmed the immunoblot results (Table 3). Ethanol- and acetate-grown pex $5 \Delta / \Delta$ cells exhibited reduced Icl1 activity, amounting to about $60 \%$ and $40 \%$, respectively, of that measured in wild-type cells while Mls1 activities were not reduced in this mutant strain. These data show that neither protein levels nor enzyme activities of Icl1 and Mls1 are reduced in the fox $2 \Delta / \Delta$ strain.

\section{fox $2 \Delta / \Delta$ cells grown on oleate or ethanol have significantly larger peroxisomes than wild-type cells}

During growth on ethanol or acetate the cytosolically formed acetyl-CoA must be transported into peroxisomes to enter the glyoxylate cycle, whereas products of this shunt, i.e. succinate and malate, have to leave the peroxisome and are shuttled to the cytosol/mitochondria. Similarly, the utilization of citrate may require the glyoxylate cycle for the generation of $\mathrm{C}_{4}$ compounds and thus shuttling of metabolites across the peroxisome membrane. Since the levels and activities of the key enzymes of the glyoxylate cycle, Icll and Mls1, are not reduced in the fox $2 \Delta / \Delta$ strain, the observed phenotype of the mutant could be explained by defective peroxisomal membrane transport of (a) metabolite(s). Previously, it has 


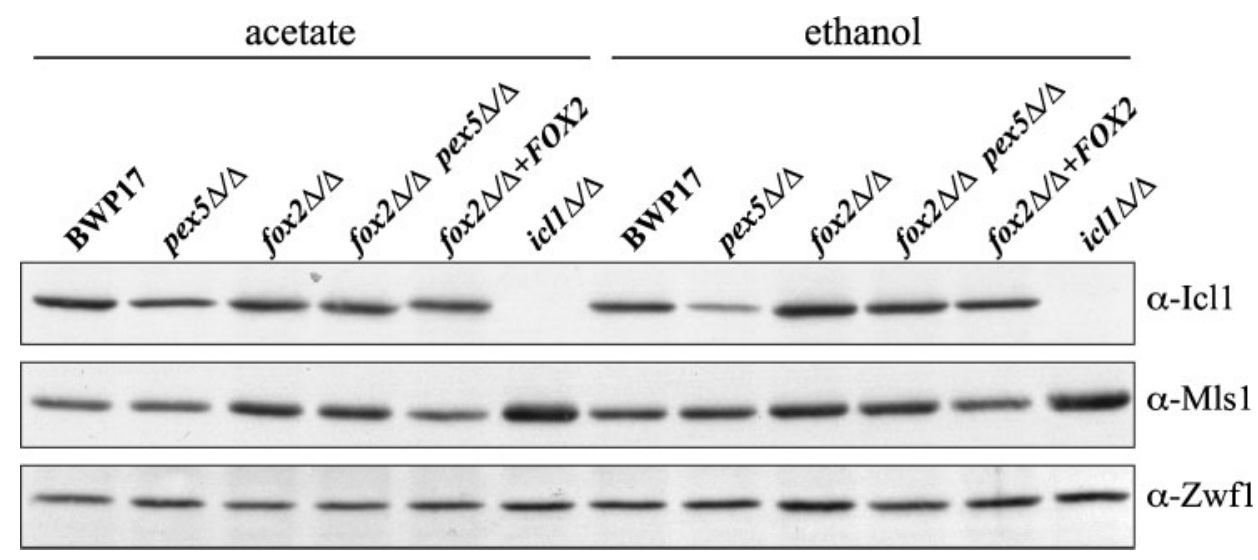

Fig. 4. Protein abundance of lcl1 and Mls1 in wild-type and mutant strains grown on ethanol or acetate. Equal amounts of total protein extracts of the indicated strains were analysed by immmunoblotting with antibodies against Icl1, Mls1 or Zwf1 (glucose6-phosphate dehydrogenase). Zwf1 served as loading control.

been observed in yeast, mammals and plants that mutants with a deficiency in peroxisomal $\beta$-oxidation exhibit a changed peroxisome size and abundance (Chang et al., 1999; Germain et al., 2001; Rylott et al., 2006; Smith et al., 2000). These observations prompted us to investigate peroxisome morphology in the fox $2 \Delta / \Delta$ strain (Fig. 2). Immunoelectron microscopy revealed that peroxisomes in oleic acid grown fox $2 \Delta / \Delta$ cells appeared more irregular in shape and larger in size than peroxisomes of wild-type cells. Morphometric analysis showed that wild-type cells did not contain peroxisomes larger than $0.6 \mu \mathrm{m}^{2}$ whereas many peroxisomes in fox $2 \Delta / \Delta$ cells had a surface area larger than $1.0 \mu \mathrm{m}^{2}$ (Fig. 5). The mean peroxisome area in fox $2 \Delta / \Delta$ cells was twice that of wild-type cells $\left(0.264 \pm 0.321 \mu \mathrm{m}^{2}\right.$ and $0.126 \pm 0.090 \mu \mathrm{m}^{2}$ for $f \circ x 2 \Delta / \Delta$ and wild-type, respectively; $P<0.0001)$. The enlarged peroxisomes were still capable of importing peroxisomal matrix proteins, as shown by the peroxisomal localization of the PTS2 enzyme thiolase and the glyoxylate cycle enzymes Icll and Mls1 (Fig. 2). Similarly, peroxisomes of fox $2 \Delta / \Delta$ cells grown on ethanol were considerably larger in size than those of wildtype cells and contained all three peroxisomal enzymes
(Figs 2 and 5). Again, morphometric analysis showed that the mean area of peroxisomes in fox $2 \Delta / \Delta$ cells was about 2.5 times that of wild-type cells $\left(0.162 \pm 0.121 \mu \mathrm{m}^{2}\right.$ for fox $2 \Delta / \Delta$ and $0.062 \pm 0.040 \mu \mathrm{m}^{2}$ for wild-type; $P<0.0001$ ). However, in contrast to what was observed for cells grown on oleic acid, peroxisomes in ethanol-grown fox $2 \Delta / \Delta$ cells were regular in shape and appeared as oval-shaped structures as normally seen in wild-type cells. These results show a clear increase in peroxisome size in the fox $2 \Delta / \Delta$ mutant, which may contribute to its inability to efficiently metabolize carbon sources that require a functional glyoxylate cycle.

\section{DISCUSSION}

In most eukaryotic organisms that utilize the glyoxylate cycle, i.e. plant seedlings, yeasts and filamentous fungi, the metabolic pathway is compartmentalized in peroxisomes. In this paper we report the localization in C. albicans of the two key glyoxylate cycle enzymes, Icll and Mls1. In subcellular fractionation experiments both proteins

Table 3. Icl1 and Mls1 enzyme activities in total protein extracts of wild-type and mutant strains

Enzyme activities are in $\mathrm{mU}(\mathrm{mg} \text { protein })^{-1}$. The results are means of two independent experiments that varied by $<15 \%$ from the mean.

\begin{tabular}{|c|c|c|c|c|}
\hline \multirow[t]{2}{*}{ Strain } & \multicolumn{2}{|c|}{ Icl1 } & \multicolumn{2}{|c|}{ Mls1 } \\
\hline & Acetate & Ethanol & Acetate & Ethanol \\
\hline Wild-type & 226.7 & 255.7 & 27.6 & 30.6 \\
\hline $\operatorname{pex} 5 \Delta / \Delta$ & 86.15 & 146.2 & 46.5 & 38.6 \\
\hline fox $2 \Delta / \Delta$ & 190.2 & 301.7 & 45.3 & 61.1 \\
\hline fox $2 \Delta / \Delta$ pex $5 \Delta / \Delta$ & 192.3 & 173.9 & 42.3 & 35.8 \\
\hline fox $2 \Delta / \Delta+F O X 2$ & 206.1 & 216.8 & 33.7 & 30.6 \\
\hline$i c l 1 \Delta / \Delta$ & 0 & 0 & 64.4 & 59.0 \\
\hline
\end{tabular}



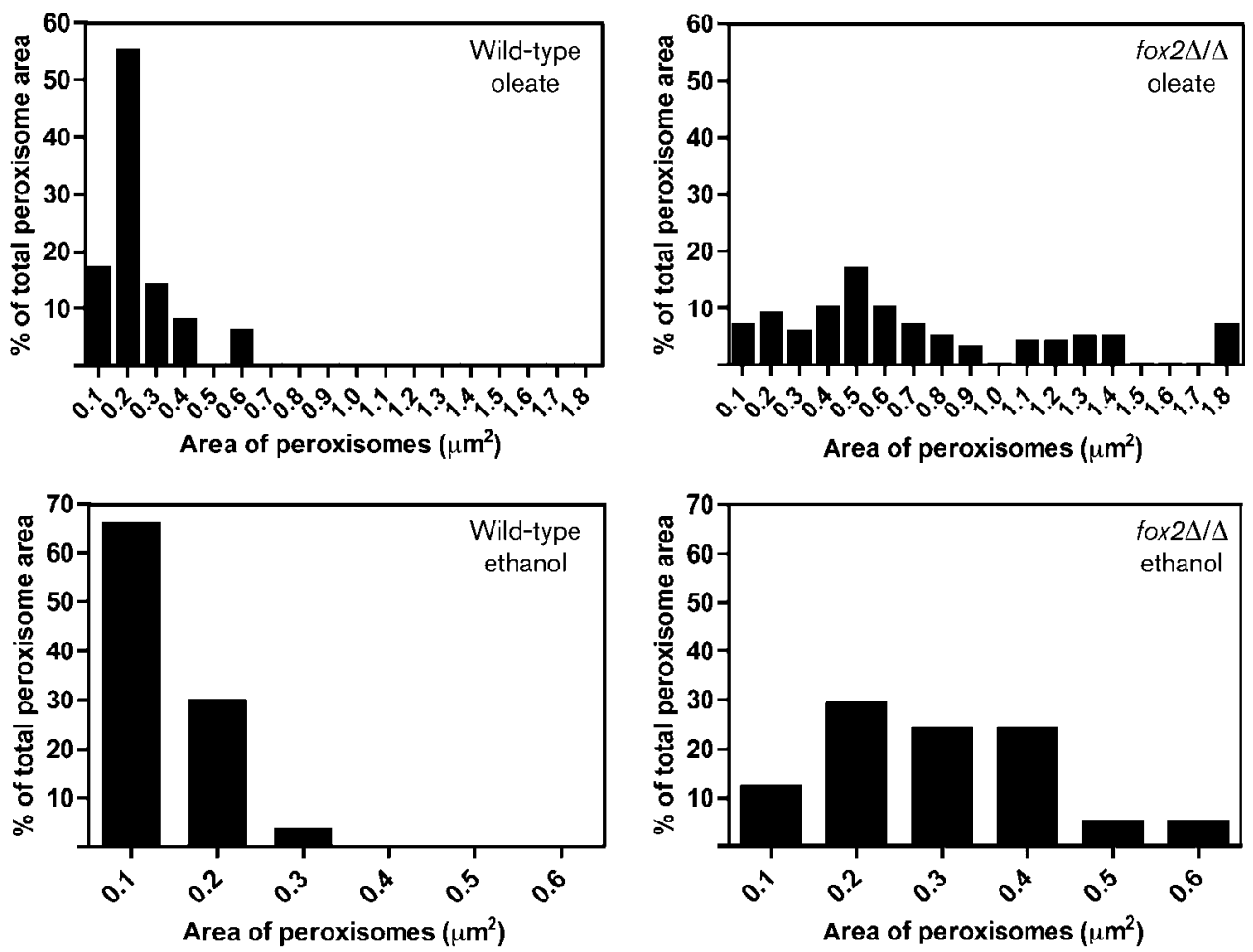

Fig. 5. Peroxisome size in wild-type and fox $2 \Delta / \Delta$ cells grown on different carbon sources. Morphometric analysis of peroxisomes was performed (see Methods) on wild-type and fox $2 \Delta / \Delta$ cells, grown on medium containing oleic acid (top panels) or ethanol (bottom panels). The number of peroxisomes counted on the micrographs for each condition was 69 (wild-type, oleate), 104 (fox $2 \Delta / \Delta$, oleate), 80 (wild-type, ethanol) and 106 (fox $2 \Delta / \Delta$, ethanol). On the $y$-axis the percentage of total peroxisome surface area occupied by the peroxisomes of each category is given. The maximum sizes of peroxisomes in each category are depicted on the $x$-axis.

co-fractionate with peroxisomal marker enzymes, and their peroxisomal localization was confirmed by immunoelectron microscopy (Figs 1 and 2). Targeting of Icl1 and Mls1 to peroxisomes appeared to be dependent on the PTS1 receptor Pex5p although neither protein has a PTS1 consensus sequence, which was defined as $\mathrm{S} / \mathrm{A} / \mathrm{C}-\mathrm{K} / \mathrm{R} / \mathrm{H}-$ L/M (Gould et al., 1989; Swinkels et al., 1992). Peroxisomal targeting of proteins in the absence of a typical PTS1 has been reported before and these studies revealed that residues upstream of the carboxyl-terminal tripeptide could play a critical role in the targeting event, with a preference for a lysine (or arginine) at the -4 position immediately preceding the non-consensus PTS1 (Lametschwandtner et al., 1998; Mullen et al., 1997; Purdue \& Lazarow, 1996). A conserved lysine residue is present at the -4 position in Icll from $C$. albicans $\left(\mathrm{KAKA}_{\mathrm{COOH}}\right)$, Candida tropicalis $\left(\mathrm{KAKV}_{\mathrm{COOH}}\right)$ castor bean $\left(\overline{\mathrm{K}}_{\mathrm{ARM}} \mathrm{COOH}\right)$ and Yarrowia lipolytica $\left(\mathrm{KSKL}_{\mathrm{COOH}}\right)$, although the latter two also contain a PTS1 that complies with the consensus sequence. In all four organisms Icll appears to be peroxisomal (Gao et al., 1996; Tanaka \& Ueda, 1993; Titorenko et al., 1998) whereas in S. cerevisiae Icll is cytosolic, which is in line with the absence of both a consensus PTS1 and a lysine at $-4 \quad\left(\mathrm{GVKK}_{\mathrm{COOH}}\right)$
(McCammon et al., 1990; Taylor et al., 1996). Whether the carboxyl-terminal four amino acids in C. albicans Icll play a role in peroxisomal targeting of the protein remains to be established, in particular since it has been shown that castor bean Icl1 can be targeted to peroxisomes in a Pex5pdependent way when the carboxyl-terminal 19 amino acids are deleted (Parkes et al., 2003). These data suggest the presence of alternative non-PTS1 targeting sequences in castor bean Icll.

C. albicans Mls1 also lacks a typical PTS1 (ERL $\left.\mathrm{COOH}_{\mathrm{H}}\right)$ and no lysine or arginine is present at the -4 position, whereas in most other organisms, e.g. Neurospora crassa, Aspergillus nidulans, S. cerevisiae and Brassica napus, a consensus PTS1 is found (either $\mathrm{SKL}_{\mathrm{COOH}}$ or $\mathrm{SRL}_{\mathrm{COOH}}$ ). The carboxylterminal tripeptide $\mathrm{ERL}_{\mathrm{COOH}}$ is also found in C. tropicalis Mls1 and the peroxisomal location of the protein has been firmly established (Hikida et al., 1991). A glutamic acid at the -3 position is also present in Mls1 of the closely related species Debaryomyces hansenii (-EKL $\mathrm{ELOH}_{\mathrm{COH}}$ ), suggesting that the PTS1 consensus of Mls1 in these species deviates from the established one and that negatively charged amino acids at the -3 position may be tolerated. Although $S$. cerevisiae Mls1 contains a typical PTS1 $\left(-\mathrm{SKL}_{\mathrm{COOH}}\right)$, the 
localization of this enzyme is not always peroxisomal but depends on the carbon source used: in oleic acid-grown cells Mls1 is peroxisomal whereas in ethanol-grown cells it is cytosolic (Kunze et al., 2002). It has been suggested that the carbon source-dependent localization of Mls1 may be advantageous to the cell, the enzyme being localized in the compartment where the acetyl-CoA, one of its substrates, is formed, i.e. peroxisomal on oleic acid and cytosolic on ethanol or acetate. Such a carbon source-dependent localization was not seen for Mls1 or Icl1 in C. albicans: both enzymes were found in peroxisomes under all conditions tested (Figs 1 and 2). Nevertheless, a peroxisomal compartmentalization of Mls1 and Icl1 is not absolutely required for proper functioning of the glyoxylate cycle since a pex5 $5 / \Delta$ strain, which mislocalizes both enzymes to the cytosol, showed wild-type growth rates on ethanol and acetate (Fig. 3) despite the reduced activity of Icl1 on these carbon sources (Table 3).

Next, we asked whether there is a correlation between the peroxisomal compartmentalization of the key enzymes of the glyoxylate cycle in C. albicans and the inability of the $\beta$ oxidation mutant fox $2 \Delta / \Delta$ to grow efficiently on $\mathrm{C}_{2}$ carbon sources (Fig. 4 and Piekarska et al., 2006; Ramírez \& Lorenz, 2007). We showed that the growth inhibition is not caused by toxicity of acetate or ethanol, and mitochondrial functions appeared to be normal in the fox $2 \Delta / \Delta$ mutant, strongly suggesting that it cannot efficiently metabolize $\mathrm{C}_{2}$ compounds. In support of this we found acetate metabolism in the fox $2 \Delta / \Delta$ mutant to be reduced to $60 \%$ of that of the wild-type strain using ${ }^{14} \mathrm{C}$-labelled acetate as substrate (data not shown). In addition to the growth deficiency on $\mathrm{C}_{2}$ compounds (and oleate), the fox $2 \Delta / \Delta$ mutant uses citrate $\left(\mathrm{C}_{6}\right)$ poorly (Ramírez \& Lorenz, 2007). The fact that the $i c l 1 \Delta / \Delta$ strain shows a similar growth defect on citrate implies that the glyoxylate cycle function is also required for the utilization of this $\mathrm{C}_{6}$ compound. We suggest that (iso)citrate must enter the glyoxylate cycle to allow the cell to generate $\mathrm{C}_{4}$ units (succinate/malate), which can be used to replenish the TCA cycle and/or function as precursors for gluconeogenesis. By deleting the PEX5 gene in the fox $2 \Delta / \Delta$ mutant, growth on ethanol and citrate could be restored partially and growth on acetate completely, consistent with our hypothesis that the observed growth phenotype of the fox $2 \Delta / \Delta$ strain on these carbon compounds may be caused by peroxisomal compartmentalization of the glyoxylate cycle. Ramírez \& Lorenz (2007) have recently suggested that the different growth phenotypes of the C. albicans and S. cerevisiae fox 2 null strains may be explained by differences in the regulatory networks governing carbon metabolism in both fungi. However, our data now strongly suggest that the different compartmentalization of glyoxylate cycle enzymes in both organisms may provide an explanation for these growth differences.

It is currently unclear why the glyoxylate cycle cannot function optimally in peroxisomes of the C. albicans fox $2 \Delta /$ $\Delta$ strain. We show here that the impaired glyoxylate cycle function in the fox $2 \Delta / \Delta$ mutant is not caused by reduced levels or activity of the key enzymes Icl1 and Mls1 (Fig. 4, Table 3). Therefore, we favour the hypothesis that the transport of metabolites (glyoxylate cycle substrates/ products and/or acetyl-CoA) across the peroxisomal membrane is affected in the fox $2 \Delta / \Delta$ strain, thereby reducing the overall rate of non-fermentable carbon metabolism. We consider two possible mechanisms: direct inhibition of peroxisomal transport proteins by activated fatty acids (acyl-CoAs) or an indirect mechanism caused by the increase in size and/or changed morphology of peroxisomes. A consequence of blocking fatty acid $\beta$ oxidation by disruption of the FOX2 gene is the accumulation of acyl-CoAs inside the cell. Even in the absence of exogenously added fatty acids such an accumulation of acyl-CoAs is likely to occur because fatty acid $\beta$-oxidation is also required for the turnover of endogenous membrane lipids. Since the peroxisome is the sole site of fatty acid $\beta$-oxidation in fungi it is conceivable that the acyl-CoA levels inside peroxisomes increase. The inhibitory effect of (long-chain) acyl-CoAs on mitochondrial carrier proteins is well documented (Morel et al., 1974) and we speculate that peroxisomal metabolite transporters may be inhibited in a similar way in the fox $2 \Delta / \Delta$ mutant. It is also possible that, due to their amphipathic nature, the acyl-CoAs insert into the peroxisomal membrane, thereby changing its physical properties and transport capabilities. An alternative mechanism is based on simple physics: when the size of the organelle increases, the surface (=membrane) area-to-volume ratio decreases, and thus large peroxisomes have relatively less membrane surface available for transport processes than small peroxisomes. Similar suggestions were put forward by Kiel et al. (2005) to explain the increase of penicillin production in Penicillium chrysogenum upon overexpression of Pex11p. Penicillin biosynthesis in P. chrysogenum occurs partially in peroxisomes and partially in the cytosol. Overexpression of Pex11p in this organism resulted in massive proliferation of small tubular-shaped peroxisomes and a 2.5-fold higher penicillin production while the level of the penicillin biosynthesis enzymes remained unchanged, suggesting that an increase in membrane-tovolume ratio may increase the transport capacity of the organelles. Further experiments are required to distinguish between these possibilities.

In conclusion, our results provide an explanation for the unexpected growth phenotypes of the $C$. albicans fox $2 \Delta / \Delta$ strain on non-fermentable carbon sources and strongly support the existence of peroxisomal metabolite transporters. Identification of such transporters may now be feasible using C. albicans as a model system.

\section{ACKNOWLEDGEMENTS}

We thank Aaron Mitchell (Columbia University, New York, USA) for providing strains and plasmids, William Fonzi (Georgetown University, Washington, USA) for plasmid pLUBP, Jürgen Wendland (Friedrich-Schiller-University, Jena, Germany) for the pFA modules, and Andreas Hartig (Vienna Biocenter, Vienna, Austria) and Sonja 
Meyer zu Berstenhorst (Insitut für Biotechnology, Jülich, Germany) for providing antibodies. We are grateful to Jan van Marle for his help with the morphometric analysis and to Rob Benne and Fred Meijer for valuable comments and suggestions. This work was supported by grants from the Academic Medical Center and the European Community (QLG2-CT-2001-01663).

\section{REFERENCES}

Aitchison, J. D. \& Rachubinski, R. A. (1990). In vivo import of Candida tropicalis hydratase-dehydrogenase-epimerase into peroxisomes of Candida albicans. Curr Genet 17, 481-486.

Boshoff, H. I. \& Barry, C. E. (2005). A low-carb diet for a high-octane pathogen. Nat Med 11, 599-600.

Bottger, G., Barnett, P., Klein, A. T., Kragt, A., Tabak, H. F. \& Distel, B. (2000). Saccharomyces cerevisiae PTS1 receptor Pex5p interacts with the SH3 domain of the peroxisomal membrane protein Pex13p in an unconventional, non-PXXP-related manner. Mol Biol Cell 11, 3963-3976.

Chang, C. C., South, S., Warren, D., Jones, J., Moser, A. B., Moser, H. W. \& Gould, S. J. (1999). Metabolic control of peroxisome abundance. J Cell Sci 112, 1579-1590.

de Jong-Gubbels, P., Vanrolleghem, P., Heijnen, S., van Dijken, J. P. \& Pronk, J. T. (1995). Regulation of carbon metabolism in chemostat cultures of Saccharomyces cerevisiae grown on mixtures of glucose and ethanol. Yeast 11, 407-418.

Elgersma, Y., van Roermund, C. W., Wanders, R. J. \& Tabak, H. F. (1995). Peroxisomal and mitochondrial carnitine acetyltransferases of Saccharomyces cerevisiae are encoded by a single gene. EMBO J 14, 3472-3479.

Elgersma, Y., Kwast, L., Klein, A., Voorn-Brouwer, T., van den Berg, M., Metzig, B., America, T., Tabak, H. F. \& Distel, B. (1996). The SH3 domain of the Saccharomyces cerevisiae peroxisomal membrane protein Pex13p functions as a docking site for Pex5p, a mobile receptor for the import PTS1-containing proteins. J Cell Biol 135, 97-109.

Gao, X., Marrison, J. L., Pool, M. R., Leech, R. M. \& Baker, A. (1996). Castor bean isocitrate lyase lacking the putative peroxisomal targeting signal 1 ARM is imported into plant peroxisomes both in vitro and in vivo. Plant Physiol 112, 1457-1464.

Germain, V., Rylott, E. L., Larson, T. R., Sherson, S. M., Bechtold, N., Carde, J. P., Bryce, J. H., Graham, I. A. \& Smith, S. M. (2001). Requirement for 3-ketoacyl-CoA thiolase-2 in peroxisome development, fatty acid beta-oxidation and breakdown of triacylglycerol in lipid bodies of Arabidopsis seedlings. Plant J 28, 1-12.

Gietl, C., Faber, K. N., van der Klei, I. J. \& Veenhuis, M. (1994). Mutational analysis of the N-terminal topogenic signal of watermelon glyoxysomal malate dehydrogenase using the heterologous host Hansenula polymorpha. Proc Natl Acad Sci U S A 91, 3151-3155.

Gillum, A. M., Tsay, E. Y. H. \& Kirsch, D. R. (1984). Isolation of the Candida albicans genes for orotidine- $5^{\prime}$-phosphate decarboxylase by complementation of $S$. cerevisiae ura 3 and E. coli pyrF mutations. Mol Gen Genet 198, 179-182.

Glover, J. R., Andrews, D. W. \& Rachubinski, R. A. (1994a). Saccharomyces cerevisiae peroxisomal thiolase is imported as a dimer. Proc Natl Acad Sci U S A 91, 10541-10545.

Glover, J. R., Andrews, D. W., Subramani, S. \& Rachubinski, R. A. (1994b). Mutagenesis of the amino targeting signal of Saccharomyces cerevisiae 3-ketoacyl-CoA thiolase reveals conserved amino acids required for import into peroxisomes in vivo. J Biol Chem 269, 7558-7563.

Gola, S., Martin, R., Walther, A., Dunkler, A. \& Wendland, J. (2003). New modules for PCR-based gene targeting in Candida albicans: rapid and efficient gene targeting using $100 \mathrm{bp}$ of flanking homology region. Yeast 20, 1339-1347.

Gould, S. J., Keller, G. A., Hosken, N., Wilkinson, J. \& Subramani, S. (1989). A conserved tripeptide sorts proteins to peroxisomes. J Cell Biol 108, 1657-1664.

Gould, S. J., Keller, G. A., Schneider, M., Howell, S. H., Garrard, L. J., Goodman, J. M., Distel, B., Tabak, H. \& Subramani, S. (1990). Peroxisomal protein import is conserved between yeast, plants, insects and mammals. EMBO J 9, 85-90.

Gueldener, U., Heinisch, J., Koehler, G. J., Voss, D. \& Hegemann, J. H. (2002). A second set of loxP marker cassettes for Cre-mediated multiple gene knockouts in budding yeast. Nucleic Acids Res 30, e23.

Hartig, A., Simon, M. M., Schuster, T., Daugherty, J. R., Yoo, H. S. \& Cooper, T. G. (1992). Differentially regulated malate synthase genes participate in carbon and nitrogen metabolism of S. cerevisiae. Nucleic Acids Res 20, 5677-5686.

Hikida, M., Atomi, H., Fukuda, Y., Aoki, A., Hishida, T., Teranishi, Y., Ueda, M. \& Tanaka, A. (1991). Presence of two transcribed malate synthase genes in an n-alkane-utilizing yeast, Candida tropicalis. J Biochem 110, 909-914.

Jones, E. W. (1977). Proteinase mutants of Saccharomyces cerevisiae. Genetics 85, 23-33.

Kamiryo, T., Abe, M., Okazaki, K., Kato, S. \& Shimamoto, N. (1982). Absence of DNA in peroxisomes of Candida tropicalis. J Bacteriol 152, 269-274.

Kiel, J. A., van der Klei, I. J., van den Berg, M. A., Bovenberg, R. A. \& Veenhuis, M. (2005). Overproduction of a single protein, Pc-Pex11p, results in 2-fold enhanced penicillin production by Penicillium chrysogenum. Fungal Genet Biol 42, 154-164.

Klein, A. T., van den Berg, M., Bottger, G., Tabak, H. F. \& Distel, B. (2002). Saccharomyces cerevisiae acyl-CoA oxidase follows a novel, non-PTS1, import pathway into peroxisomes that is dependent on Pex5p. J Biol Chem 277, 25011-25019.

Kornberg, H. L. \& Krebs, H. A. (1957). Synthesis of cell constituents from C2-units by a modified tricarboxylic acid cycle. Nature 179, 988-991.

Kunze, M., Kragler, F., Binder, M., Hartig, A. \& Gurvitz, A. (2002). Targeting of malate synthase 1 to the peroxisomes of Saccharomyces cerevisiae cells depends on growth on oleic acid medium. Eur J Biochem 269, 915-922.

Lametschwandtner, G., Brocard, C., Fransen, M., Van Veldhoven, P., Berger, J. \& Hartig, A. (1998). The difference in recognition of terminal tripeptides as peroxisomal targeting signal 1 between yeast and human is due to different affinities of their receptor Pex $5 p$ to the cognate signal and to residues adjacent to it. J Biol Chem 273, 33635-33643.

Lorenz, M. C. \& Fink, G. R. (2001). The glyoxylate cycle is required for fungal virulence. Nature 412, 83-86.

Lorenz, M. C. \& Fink, G. R. (2002). Life and death in a macrophage: role of the glyoxylate cycle in virulence. Eukaryot Cell 1, 657-662.

Lorenz, M. C., Bender, J. A. \& Fink, G. R. (2004). Transcriptional response of Candida albicans upon internalization by macrophages. Eukaryot Cell 3, 1076-1087.

Maeting, I., Schmidt, G., Sahm, H., Revuelta, J. L., Stierhof, Y. D. \& Stahmann, K. P. (1999). Isocitrate lyase of Ashbya gossypii-transcriptional regulation and peroxisomal localization. FEBS Lett 444, 15-21.

McCammon, M. T., Veenhuis, M., Trapp, S. B. \& Goodman, J. M. (1990). Association of glyoxylate and beta-oxidation enzymes with peroxisomes of Saccharomyces cerevisiae. J Bacteriol 172, 5816-5827.

McKinney, J. D., Honer zu Bentrup, K., Munoz-Elias, E. J., Miczak, A., Chen, B., Chan, W. T., Swenson, D., Sacchettini, J. C., Jacobs, W. R., Jr \& Russell, D. G. (2000). Persistence of Mycobacterium tuberculosis in macrophages and mice requires the glyoxylate shunt enzyme isocitrate lyase. Nature 406, 735-738. 
McNew, J. A. \& Goodman, J. M. (1994). An oligomeric protein is imported into peroxisomes in vivo. J Cell Biol 127, 1245-1257.

Morel, F., Lauquin, G., Lunardi, J., Duszynski, J. \& Vignais, P. V. (1974). An appraisal of the functional significance of the inhibitory effect of long chain acyl-CoAs on mitochondrial transports. FEBS Lett 39, 133-138.

Mullen, R. T., Lee, M. S., Flynn, C. R. \& Trelease, R. N. (1997). Diverse amino acid residues function within the type 1 peroxisomal targeting signal. Implications for the role of accessory residues upstream of the type 1 peroxisomal targeting signal. Plant Physiol 115, 881-889.

Munoz-Elias, E. J. \& McKinney, J. D. (2005). Mycobacterium tuberculosis isocitrate lyases 1 and 2 are jointly required for in vivo growth and virulence. Nat Med 11, 638-644.

Ozimek, P., Kotter, P., Veenhuis, M. \& van der Klei, I. J. (2006). Hansenula polymorpha and Saccharomyces cerevisiae Pex5p's recognize different, independent peroxisomal targeting signals in alcohol oxidase. FEBS Lett 580, 46-50.

Parkes, J. A., Langer, S., Hartig, A. \& Baker, A. (2003). PTS1independent targeting of isocitrate lyase to peroxisomes requires the PTS1 receptor Pex5p. Mol Membr Biol 20, 61-69.

Pellicer, M. T., Fernandez, C., Badia, J., Aguilar, J., Lin, E. C. \& Baldom, L. (1999). Cross-induction of $g l c$ and ace operons of Escherichia coli attributable to pathway intersection. Characterization of the glc promoter. J Biol Chem 274, 1745-1752.

Piekarska, K., Mol, E., van den Berg, M., Hardy, G., van den Burg, J., van Roermund, C., Maccallum, D., Odds, F. \& Distel, B. (2006). Peroxisomal fatty acid $\beta$-oxidation is not essential for virulence of Candida albicans. Eukaryot Cell 5, 1847-1856.

Purdue, P. E. \& Lazarow, P. B. (1996). Targeting of human catalase to peroxisomes is dependent upon a novel $\mathrm{COOH}$-terminal peroxisomal targeting sequence. J Cell Biol 134, 849-862.

Purdue, P. E. \& Lazarow, P. B. (2001). Peroxisome biogenesis. Annu Rev Cell Dev Biol 17, 701-752.

Ramírez, M. A. \& Lorenz, M. C. (2007). Mutations in alternative carbon utilization pathways in Candida albicans attenuate virulence and confer pleiotropic phenotypes. Eukaryot Cell 6, 280-290.

Rylott, E. L., Eastmond, P. J., Gilday, A. D., Slocombe, S. P., Larson, T. R., Baker, A. \& Graham, I. A. (2006). The Arabidopsis thaliana multifunctional protein gene (MFP2) of peroxisomal beta-oxidation is essential for seedling establishment. Plant J 45, 930-941.
Sambrook, J., Fritsch, E. F. \& Maniatis, T. (1989). Molecular Cloning: A Laboratory Manual, 2nd edn. Cold Spring Harbor, NY: Cold Spring Harbor Laboratory.

Schmidt, G., Stahmann, K. P., Kaesler, B. \& Sahm, H. (1996). Correlation of isocitrate lyase activity and riboflavin formation in the riboflavin overproducer Ashbya gossypii. Microbiology 142, 419-426.

Small, G. M., Szabo, L. J. \& Lazarow, P. B. (1988). Acyl-CoA oxidase contains two targeting sequences each of which can mediate protein import into peroxisomes. EMBO J 7, 1167-1173.

Smith, J. J., Brown, T. W., Eitzen, G. A. \& Rachubinski, R. A. (2000). Regulation of peroxisome size and number by fatty acid beta-oxidation in the yeast Yarrowia lipolytica. J Biol Chem 275, 20168-20178.

Swinkels, B. W., Gould, S. J. \& Subramani, S. (1992). Targeting efficiencies of various permutations of the consensus C-terminal tripeptide peroxisomal targeting signal. FEBS Lett 305, 133-136.

Tanaka, A. \& Ueda, M. (1993). Assimilation of alkanes by yeasts function and biogenesis of peroxisomes. Mycol Res 97, 1025-1044.

Taylor, K. M., Kaplan, C. P., Gao, X. \& Baker, A. (1996). Localization and targeting of isocitrate lyases in Saccharomyces cerevisiae. Biochem J 319, 255-262.

Titorenko, V. I., Smith, J. J., Szilard, R. K. \& Rachubinski, R. A. (1998). Pex20p of the yeast Yarrowia lipolytica is required for the oligomerization of thiolase in the cytosol and for its targeting to the peroxisome. J Cell Biol 142, 403-420.

Valenciano, S., Lucas, J. R., Pedregosa, A., Monistrol, I. F. \& Laborda, F. (1996). Induction of beta-oxidation enzymes and microbody proliferation in Aspergillus nidulans. Arch Microbiol 166, 336-341.

Walther, A. \& Wendland, J. (2003). An improved transformation protocol for the human fungal pathogen Candida albicans. Curr Genet 42, 339-343.

Wilson, R. B., Davis, D. \& Mitchell, A. P. (1999). Rapid hypothesis testing with Candida albicans through gene disruption with short homology regions. J Bacteriol 181, 1868-1874.

Yang, X., Purdue, P. E. \& Lazarow, P. B. (2001). Ecilp uses a PTS1 to enter peroxisomes: either its own or that of a partner, Dcilp. Eur $J$ Cell Biol 80, 126-138.

Edited by: J. F. Ernst 